\title{
EDITORIAL
}

\section{SOBRE A REVISTA ARCHEION ONLINE}

No seu histórico, a revista, que se vincula ao curso de Bacharelado em Arquivologia da Universidade Federal da Paraíba (UFPB), informa que surgiu a partir da necessidade de divulgar a produção científica dos alunos de Arquivologia e seus orientadores, bem como os resultados de pesquisas na pós-graduação em Ciência da Informação. O texto esclarece que Archeion Online é uma transposição da ideia de "Archeion", que pode ser traduzido como "o lugar onde se redige e conserva os documentos".1

A edição da revista tornou-se possível no âmbito do Movimento de Acesso Livre à Informação Científica, liderado pelo Instituto Brasileiro de Informação em Ciência e Tecnologia, que customizou e disponibilizou a plataforma Open Journals System, traduzida como Sistema Eletrônico de Editoração de Revistas, propiciando um incremento na edição de periódicos científicos brasileiros, em geral, e nas áreas de Ciência da Informação, Biblioteconomia e Arquivologia, em particular. Pois, desde meados do século XIX, os periódicos científicos são o canal de comunicação por excelência da comunidade científica e seu acesso livre on line representa um inestimável apoio à divulgação das ciências e das atividades do campo científico. ${ }^{2}$

A revista Archeion online está, indexada nas seguintes bases: Sumários de Revistas Brasileiras ${ }^{3}$, LATINDEX ${ }^{4}$, Directory of Open Access Journals ${ }^{5}$, Portal de Periódicos da UFPB ${ }^{6}$ e Base de dados em Ciência da Informação ${ }^{7}$.

O Qualis-Periódicos, sistema usado pela Capes para "classificar a produção científica dos programas de pós-graduação no que se refere aos artigos publicados em

\footnotetext{
${ }^{1}$ Histórico. Disponível em: http://periodicos.ufpb.br/ojs2/index.php/archeion/about/history.

${ }^{2}$ Sobre as Revistas no SEER, consulte: http://seer.ibict.br/index.php?option=com_mtree\&Itemid=109.

${ }^{3}$ Sumários.Org. Disponível em: http://www.sumarios.org/.

${ }^{4}$ Sistema Regional de Información en Línea para Revistas Científicas de América Latina, el Caribe, España y Portugal. Disponível em: http://www.latindex.org/latindex/ficha?folio=24621.

${ }^{5}$ DOAJ. Disponível em: https://doaj.org/.

${ }^{6}$ Disponível em: https://periodicos.ufpb.br.

${ }^{7}$ BRAPCI. Disponível em http://www.brapci.ufpr.br/brapci/.
} 
periódicos científicos", incluiu, em 2016, a Archeion Online no seu sistema de classificação. Essa avaliação é realizada por comitês de consultores de áreas, "seguindo critérios previamente definidos pela área [...], que procuram refletir a importância relativa dos diferentes periódicos para uma determinada área". ${ }^{8}$

Conforme a Capes, um mesmo periódico pode ser classificado em duas ou mais áreas científicas, recebendo diferentes avaliações, o que não constituiria inconsistência, mas expressaria o valor atribuído, em cada área, à pertinência do conteúdo veiculado pelo periódico científico.

A Capes esclarece, também, que apenas os periódicos que tenham recebido produção no período de classificação serão listados e classificados no Qualis, de modo que não se trata de uma lista exaustiva de periódicos, mas, sim, de uma lista de periódicos efetivamente utilizados pelos programas de pós-graduação no período em análise.

Nesse sentido, no Qualis de Peródicos a Archeion Online foi classificada como C na área de Comunicação e Informação, como B4 nas áreas de Psicologia e Interdisciplinar, e como B3 para a área de Administração pública e de empresas, Ciências Contábeis e de Turismo. 0 que ressalta a relevância da classificação da Archeion Online em outras áreas científicas, característica que, por sua, vez, ressalta o caráter interdisciplinar da Arquivologia.

O presente número contempla um Artigo de Revisão e cinco Relatos de Pesquisas.

O Artigo de Revisão intitula-se Primeiras aproximações teóricas do ator-rede na arquivologia, da autora: Patrícia Silva, é um ensaio teórico que traz uma temática nova para a área da arquivologia com uma perspectiva sobre a ontologia dos objetos a partir da Teoria Ator-Rede (ANT). 0 artigo representa uma crítica à visão antropocêntrica de mundo tendo em vista que o pensamento pós-humanista incorpora atores não humanos como elementos essenciais para a compreensão do social.

O primeiro Relato de Pesquisa se intitula $A$ análise da produção científica no periódico eletrônico Archeion Online, tendo como autores Aurekelly Rodrigues da Silva,

\footnotetext{
${ }^{8}$ Capes - Classificação da Produção Intelectual. Disponível em: http://www.capes.gov.br/avaliacao/instrumentos-de-apoio/classificacao-da-producao-intelectual.
} 
Jefferson Fernandes Dantas, Gisele Rocha Cortes e Leyde Klebia Rodrigues da Silva. Esta pesquisa identifica as temáticas abordadas nos artigos publicados, além de trazer um breve panorama histórico da revista.

O segundo, com o título A pesquisa etnográfica no arquivo pessoal de Nelson Coelho de Senna, é uma pesquisa realizada por: Maristela Costa Martiniano e Rubens Alves da Silva, que aborda a temática etnográfica especialmente em arquivos pessoais, trazendo discussões sobre o africanismo a partir de documentos de Nelson Coelho de Senna.

O terceiro tem o título Estudo de usuário do Núcleo de Documentação de pessoal e informação da Universidade Federal da Paraíba, das autoras Karlla Karollina Almeida Felix e Joana Coeli Ribeiro Garcia, resulta de pesquisa para Trabalho de Conclusão de Curso apresentado no Curso de Arquivologia da Universidade Federal da Paraíba, onde identifica o perfil e a satisfação dos usuários do Núcleo de Documentação de Pessoal e Informação (NDPI) da UFPB, possibilitando conhecer com mais propriedade o usuário e avaliar o desempenho dos serviços oferecidos pelo arquivo.

O quarto se intitula Panorama da atuação do profissional arquivista, das autoras: Sonia Scoralick de Almeida e Emeide Nóbrega Duarte, esta pesquisa contribui para a área da arquivologia no que concerne a atuação do arquivista no âmbito da UFPB, a partir da Lei 6546/78 e do Projeto Político Pedagógico (PPP) do curso de arquivologia da mesma instituição, traz ainda sugestões para atender as demandas de gestão de arquivos universitários.

O quinto apresenta como título Plano de marketing - compromisso na busca de resultados: entre o saber e o fazer no arquivo central do IFPB, das autoras Sildete Pereira da Silva e Edna Gomes Pinheiro, aborda a gestão de arquivos a partir da visão de mercado, onde o marketing é preponderante nas decisões com vistas a melhorias dos serviços e da relação do usuário com o arquivo.

De modo que revista vem cumprindo seu papel de "estimular e publicizar artigos [...] originados [de] pesquisas que enriqueçam a área [de modo a contribuir] para o alinhamento entre teoria e prática", na formação profissional e científica. Nas palavras 
da Editora da Archeion Online, é "gratificante participar de um processo de construção de conhecimentos que contribui para o desenvolvimento científico". 9

Para nós, leitores, autores, avaliadores, também é gratificante participar desse processo exitoso de construção editorial, e, por isso mesmo, creio que também os represento quando registro, aqui, um voto de "Longa e produtiva vida à Archeion Online!".

\section{Isa Maria Freire}

Professora Associada do Departamento de Ciênciada Informação da UFPB Docente permanente do Programa de Pós-Graduação em Ciência da Informação da UFPB Editora Científica da revista Informação\&Sociedade: Estudos Editora-chefe da revista Pesquisa Brasileira em Ciência da Informação e Biblioteconomia

\footnotetext{
${ }^{9}$ CARVALHO, E.T.G. de. Avançando para novos rumos de qualidade. Archeion Online, v.4, n.2, p.2-3, 2016. Editorial. Disponível em: http://periodicos.ufpb.br/ojs2/index.php/archeion/article/view/32303/16930.
} 